Check for updates

The BMJ

Cite this as: $B M J 2021 ; 375: n 3092$

http://dx.doi.org/10.1136/bmi.n3092

Published: 15 December 2021

\title{
Covid-19: Long covid symptoms among hospital inpatients show little improvement after a year, data suggest
}

\author{
Ingrid Torjesen
}

People admitted to hospital with covid-19 who reported "long covid" symptoms five months after discharge had made only limited improvement after a full year, preliminary data from the PHOSP-COVID study show.

Researchers said that their results, released as a preprint on 16 December, ${ }^{1}$ showed that patients who experienced the most severe symptoms also had raised levels of substances associated with whole body inflammation and tissue damage and repair, suggesting autoimmune involvement.

The study, led by the National Institute for Health Research (NIHR) Leicester Biomedical Research Centre, is following up 2230 adults admitted to hospital with covid-19. At five months after discharge only 2.5 in 10 people felt fully recovered. ${ }^{2}$ This was largely unchanged after 12 months, at less than 3 in 10 patients, in the 807 people assessed so far.

Chris Brightling, professor of respiratory medicine at the University of Leicester and chief investigator for the study, said, "People who were hospitalised and went on to develop long covid are not getting substantially better a year after they were discharged from hospital.

"Many patients in our study had not fully recovered at five months, and most of these reported little positive change in their health condition at one year."

Rachael Evans, associate professor at the University of Leicester and respiratory consultant at Leicester's Hospitals, who is the paper's lead author, said, "Healthcare professionals will need to proactively continue assessing their patients for some time to come in order to identify their ongoing healthcare needs and provide support.

"We urgently need healthcare packages and medicines that target the potentially treatable traits of long covid to help people feel better and get back to their normal lives. Without these, long covid has the potential to become highly prevalent as a new long term condition."

\section{Ongoing inflammatory process}

The most common long covid symptoms reported by patients were fatigue, muscle pain, physically slowing down, poor sleep, and breathlessness, and patients said that their health related quality of life remained substantially worse one year after hospital discharge than before they had the SARS-CoV-2 infection.

A cluster analysis on the five month data revealed four distinct groups of patients based on the severity of symptoms they experienced: in 39\% symptoms were considered mild, in $30 \%$ severe, in $20 \%$ very severe, and in $11 \%$ they were moderate or primarily affected cognition.

Blood samples taken at five months were analysed for around 300 substances linked to inflammation and immunity. These showed that patients in the "very severe" group had higher levels of substances associated with whole body inflammation, tissue damage, and tissue repair, while those reporting poor cognition appeared to have higher levels of substances linked to "brain fog," suggesting possible neuro-inflammation.

Brightling said that the results suggested "an ongoing inflammatory process" and that other studies had indicated an increase in autoimmunity in some cases against specific organs such as heart or skeletal muscle. "We're working very closely with immunologists to try to unpick that and see whether autoimmunity may be one of the key drivers [of long covid]," he said.

\section{Evans RA, Leavy OC, Richardson M, et al. Clinical characteristics with inflammation profiling of long-covid and association with one-year recovery following hospitalisation in the UK: a prospective observational study. medRxiv 2021 Dec 15 [preprint]. https://www.medrxiv.org/con- tent/10.1101/2021.12.13.21267471v1doi: 10.1101/2021.12.13.21267471 \\ 2 Torjesen I. Covid-19: Middle aged women face greater risk of debilitating long term symptoms. BMJ 2021;372:n829. doi: 10.1136/bmj.n829 pmid: 33766927}

This article is made freely available for use in accordance with BMJ's website terms and conditions for the duration of the covid-19 pandemic or until otherwise determined by BMJ. You may use, download and print the article for any lawful, non-commercial purpose (including text and data mining) provided that all copyright notices and trade marks are retained. 